\title{
Delayed diagnosis and associated factors among new pulmonary tuberculosis patients diagnosed at the emergency department of a tertiary care hospital in Porto Alegre, South Brazil: a prospective patient recruitment study
}

\author{
Gracieli Nadalon Deponti, Denise Rossato Silva, Ana Cláudia Coelho, Alice Mânica Muller \\ and Paulo de Tarso Roth Dalcin
}

\begin{abstract}
Background: Control of tuberculosis (TB) depends on early diagnosis and treatment at the primary health care level. However, many patients are still diagnosed late with TB at hospitals. The present study aimed to investigate the delay in diagnosis of TB patients at the emergency department.

Methods: This was a prospective study in a general, tertiary care, university-affiliated hospital of a city with a high prevalence of TB in Brazil. New TB patients $\geq 14$ years diagnosed with pulmonary TB at the emergency department of Hospital de Clínicas de Porto Alegre were prospectively recruited between February 2010 and January 2012. The consenting patients meeting our inclusion criteria were interviewed using a pre-tested questionnaire. We evaluated the delay in time until diagnosis and identified factors associated with delayed diagnosis (patient and health care system delays).

Results: We included 153 patients. The median total time of delay, patient delay, and health care system delay were 60 (interquartile range [IQR]: 30-90.5 days), 30 (IQR: 7-60 days), and 18 (IQR: 9-39.5 days) days, respectively. The factors that were independently associated with patient delay (time $\geq 30$ days) were crack (odds ratio $[\mathrm{OR}]=4.88$, $p=0.043)$ and cocaine $(O R=6.68, p=0.011)$ use. The factors that were independently associated with health care system delay (time $\geq 18$ days) were weight loss $(O R=2.76, p=0.025)$, miliary pattern $(O R=5.33, p=0.032)$, and fibrotic changes $(\mathrm{OR}=0.12, \mathrm{p}=0.013)$ on chest $\mathrm{X}$-ray.
\end{abstract}

Conclusions: Patient delay appears to be the main problem in this city with a high prevalence of TB in Brazil. The main factor associated with patient delay is drug abuse (crack and cocaine). Our study shows substance abuse programs need to be aware of control of TB, with health interventions focusing on TB education programs.

Keywords: Tuberculosis, Risk factors, Patient delay, Health care system delay, Diagnosis

\footnotetext{
* Correspondence: gracideponti@yahoo.com.br

Universidade Federal do Rio Grande do Sul (UFRGS), Programa de Pós-Graduação em Ciências Pneumológicas da UFRGS, Serviço de Pneumologia, Hospital de Clínicas de Porto Alegre (HCPA), Porto Alegre, Brazil
} 


\section{Background}

Tuberculosis (TB) is an infectious disease caused by Mycobacterium tuberculosis and remains a public health problem worldwide. Approximately 2 billion people, representing one third of the world's population, are infected with TB. Eight million people develop active disease each year, resulting in 2 million deaths from TB annually. Brazil is ranked $17^{\text {th }}$ among 22 countries, and has the highest reported incidence of TB, with 42 cases/100,000 inhabitants in 2011 [1]. The city of Porto Alegre in southern Brazil had a rate of incidence of TB in 104 cases/100,000 inhabitants/ year in 2011 [2].

Control of TB in the community depends on early diagnosis and treatment. In regions with a high prevalence of TB, an early diagnosis is considered as one performed between 2 to 3 weeks after the onset of clinical symptoms and a late diagnosis is that performed 4 weeks after this onset [3]. Therefore, an acceptable time delay in diagnosis of 3 or 4 weeks would be effective for disease control [4]. The total diagnosis delay is the sum of patient delay, and health system delay. The reported ranges of the average (median or mean) total diagnosis delay, patient delay, and health system delay are 25-185 days, 4.9162 days, and 2-87 days, respectively, for low, middle, and high income countries [5].

The reasons for delay in diagnosis reflect factors related to the patient and the health care system. Factors related to the health system vary according to each country or region [6]. The factors related to the individual involve personal characteristics, and socioeconomic and demographic factors $[6,7]$. The main factors associated with diagnostic delay include human immunodeficiency virus (HIV) infection, a negative sputum smear, extrapulmonary $\mathrm{TB}$, old age, female sex, alcoholism and substance abuse, low education level, coexistence of chronic cough and/or other lung diseases, rural residence, low access, low awareness of TB, among others [6]. In studies conducted in Brazil, female sex, cough, unemployment, and the inability to recognize symptoms as indicators of disease are factors independently associated with patient delay $[8,9]$. In addition, only female sex is independently associated with health care system delay [8]. Furthermore, unemployment, having given up smoking, and having lost weight are associated with total delay (patient and health care system delays) [10].

Understanding the factors related to delay in diagnosis of disease is essential to reduce the period of transmission, reduce the risk of exposure of other community members, and thus facilitate disease control. Few studies have evaluated these factors in tertiary care hospitals in regions with a high incidence of TB and HIV $[6,11]$. The objective of this study was to investigate the delay in diagnosis of TB patients at the emergency department (ED) of a tertiary care hospital, and to analyze factors associated with patient and health care system delays.

\section{Methods}

\section{Study design and setting}

We conducted a prospective study at the ED of the Hospital de Clinicas de Porto Alegre (HCPA). The HCPA is a tertiary hospital and a reference center for HIV patients in South Brazil. Porto Alegre is among the Brazilian cities with the highest incidence of TB, with 2123 cases registered in 2011, 200 deaths in patients co-infected with TB-HIV, and 50 deaths in patients who were HIV negative [2]. Furthermore, Porto Alegre has a TB-HIV co-infection rate of 35\% [12]. In Brazil, the public health system provides TB health services and treatment free of charge at hospitals and health centers.

\section{Participants}

The study population consisted of patients diagnosed with TB at the ED. Patients aged more than 14 years, diagnosed as new cases of pulmonary TB (with or without extrapulmonary TB), according to consensus criteria [13], were included in the study. The study was approved by the Research Ethics Committee of the HCPA (protocol 09-575). All patients or their legal guardians gave written informed consent to participate.

Pulmonary TB was diagnosed according to any of the following criteria established by the Brazilian Guidelines for Tuberculosis [13]: 1) detection by a direct test (Ziehl-Neelsen [ZN] method) with two positive samples; 2) detection by a direct test ( $\mathrm{ZN}$ method) with one positive sample and a positive culture result for $M$. tuberculosis (in Löwenstein-Jensen [LJ] medium); 3) detection by a direct test (ZN method) with one positive sample and radiological findings compatible with TB; 4) only a positive culture result for $M$. tuberculosis (in LJ medium); or 5) the presence of clinical, epidemiological, and radiographic findings compatible with TB. Patients who failed to respond to questionnaires and those who refused to sign the consent form were excluded from the study.

\section{Data collection}

For data collection, we used a standardized and pre-tested questionnaire with open and closed questions. The interviews were conducted by three interviewers who were previously trained at the time of admission. Factors that could be associated with delay in seeking care at health services, and delay in diagnosis and initiation of treatment for $\mathrm{TB}$ were collected. These factors included demographic characteristics, such as age (years), sex (male/female), ethnicity (white/non-white race), income (monthly household income), and education level (years of schooling). Behavioral characteristics included (1) smoking status as follows. Respondents who reported smoking at least 100 cigarettes in their lifetime and who, at the time of survey, smoked either every day or some days were defined as current smokers. Respondents who reported smoking at least 100 cigarettes 
in their lifetime and who, at the time of the survey, did not smoke at all were defined as former smokers. Respondents who reported never having smoked 100 cigarettes were defined as never smokers. (2) Alcohol use was investigated where alcohol abuse was defined as daily consumption of at least $30 \mathrm{~g}$ of alcohol for men and $24 \mathrm{~g}$ for women.

(3) Drug use was defined as any use in the past 6 months.

(4) Self-medication use was recorded. Clinical features of the disease included the clinical form of TB (pulmonary or pleuropulmonary), symptoms (cough, sputum production, night sweats, weight loss, fever, dyspnea, hemoptysis, chest pain, and fatigue), time since the first symptom, HIV status (patients were tested for HIV at the discretion of the ER physician), non-HIV immunosuppression (chronic renal failure, malignant tumors, transplant recipients, and those using prednisone or an equivalent (at a dose $\geq 15 \mathrm{mg}$ /day for 4 weeks]), immunosuppressants (for 4 weeks or longer) or biological modifiers, such as etanercept and infliximab. Services sought before the ED (if yes or no, and the number of services sought), and the history of previous TB (and if the patient completed at least 6 months of treatment) were also collected. The diagnostic method (spontaneous sputum, induced sputum, and bronchoalveolar lavage) and chest X-ray results were obtained from the electronic medical records.

Patients were asked to estimate the time in days from onset of symptoms to the first clinical care (any clinicians, not only in the ED). The total time of delay was defined as the period from the beginning of any symptoms until the use of at least three antituberculosis drugs. Patient delay was defined as the period from the beginning of any symptoms of TB until the first medical care. Health system delay was defined as the period from the first medical care until the beginning of at least three antituberculosis drugs.

\section{Sample size calculation and statistical analysis}

Calculation of sample size was performed based on a study by Ward et al. [14], where the variable that was significantly associated with delayed initiation of treatment in the health system was an age greater than 45 years (the prevalence of an age $>45$ years was $59 \%$ ). A previous study in the HCPA showed that the prevalence of an age greater than 45 years in patients with TB was 60\% [15]. Therefore, considering a difference between the proportions in groups (patient delay [ $\geq 30$ days versus $<30$ days] and health system delay [ $\geq 18$ days versus $<18$ days]) of $25 \%$, with the lower proportion of $40 \%, \alpha=0.05$, and $\beta=20 \%$, the total number of patients needed to be studied was 69 in each group.

The median patient delay and health care system delay were used to dichotomize the sample for analysis. Patients were evaluated according to patient delay (group $1: \geq 30$ days versus group $2:<30$ days) and health system delay (group 1: $\geq 18$ days versus group 2: < 18 days). Data analysis was performed using SPSS 18.0 (Statistical Package for the Social Sciences, Chicago, IL). Data are shown as the number of cases, mean \pm standard deviation (SD), or median with interquartile range (IQR). Categorical comparisons were performed by the chi-square test using Yates's correction if indicated or by Fisher's exact test. Continuous variables were compared using the $t$-test or Wilcoxon test. Multivariate logistic regression analysis was used to evaluate risk factors for patient and health care system delays. Multivariate logistic regression modeling attempted to use all factors associated $(\mathrm{p}<0.10)$ with the outcome in univariate models. Stepwise logistic regression, with entry criteria of $p<0.10$ and removal criteria of $p>0.05$, was used to establish the final multivariate predictive model. This type of variable selection with bivariable selection is frequently used because nonsignificant risk factors in bivariable analysis may actually be significant risk factors in multivariable analysis. If the statistical $p$ value of a risk factor in bivariable analysis is greater than an arbitrary value (often $\mathrm{p}=0.1$ ), then this factor will be allowed to compete for inclusion in multivariable analysis. Hierarchical logistic regression models with predictors added one at a time were also examined to evaluate possible collinearity among the predictors. The predictors selected in the final model were based on numerical and clinical significance. The goodness of fit of the multiple logistic regression models was assessed using the Hosmer-Lemeshow test. Odds ratios (ORs) and nominal 95\% confidence intervals (CIs) are presented. A two-sided $\mathrm{p}$ value $<0.05$ was considered significant for all analyses.

\section{Results}

\section{General results}

From February 2010 to January 2012, 418 patients were eligible for the study. Among pulmonary TB patients, we excluded 248 patients who were already receiving treatment at admission, 12 patients who refused to participate, and five patients because TB diagnosis was not confirmed. Therefore, 153 patients were included in the study.

Table 1 shows the patients' characteristics. The median total delay (from onset of symptoms to initiation of treatment) was 60 days. The median patient delay was 30 days and the median health care system delay was 18 days.

\section{Patient delay}

Table 2 shows comparative analysis for patient delay. Compared with Group 2 ( $<30$ days for patient delay), Group 1 ( $\geq 30$ days for patient delay) had a significantly higher proportion of cocaine use (27.8 versus $6.8 \%$, $\mathrm{p}=0.001$ ) and crack use (31.6 versus $13.5 \% ; \mathrm{p}=0.013$ ). The proportion of patients who sought treatment at another facility before going to the ED was significantly higher in 
Table 1 Patients' characteristics

\begin{tabular}{|c|c|}
\hline Characteristics & $n=153$ \\
\hline Age, years (mean $\pm S D)$ & $42.6 \pm 15.7$ \\
\hline Male sex, n (\%) & $90(58.8)$ \\
\hline White race, n (\%) & $88(57.5)$ \\
\hline$<8$ years schooling, $\mathrm{n}(\%)$ & $81(52.9)$ \\
\hline Literate, n (\%) & $141(92.2)$ \\
\hline Living alone, n (\%) & $30(19.6)$ \\
\hline Belief in a religion, $\mathrm{n}(\%)$ & $126(82.4)$ \\
\hline $\begin{array}{l}\text { Monthly household income }<1 \text { standard minimum } \\
\text { wage }^{*}, \mathrm{n}(\%)\end{array}$ & $51(33.3)$ \\
\hline Living in Porto Alegre, n (\%) & $101(66.0)$ \\
\hline Institutionalization, n (\%) & $23(15)$ \\
\hline \multicolumn{2}{|l|}{ Smoking habit, n (\%) } \\
\hline Never smoker & $55(35.9)$ \\
\hline Current smoker & $42(27.5)$ \\
\hline Former smoker & $56(36.6)$ \\
\hline Alcoholism, n (\%) & $53(34.6)$ \\
\hline Drug use, n (\%) & $50(32.7)$ \\
\hline Marijuana, n (\%) & $29(19.0)$ \\
\hline Cocaine use, n (\%) & $27(17.6)$ \\
\hline Crack use, n (\%) & $35(22.9)$ \\
\hline HIV positive, n (\%) & $77(51.1)$ \\
\hline Non-HIV immunosuppression, n (\%) & $22(14.4)$ \\
\hline Sought care elsewhere before hospitalization, n (\%) & $113(73.9)$ \\
\hline \multicolumn{2}{|l|}{ Forms of TB, n (\%) } \\
\hline Pulmonary TB & $127(83.0)$ \\
\hline Milliary TB & $19(12.4)$ \\
\hline Pleuropulmonary TB & $7(4.6)$ \\
\hline Total time until diagnosis (days), median (IR) & $60.0(30.0-90.5)$ \\
\hline Patient delay (days), median (IR) & $30.0(7.0-60.0)$ \\
\hline Health care system delay (days), median (IR) & $18.0(9.0-39.5)$ \\
\hline
\end{tabular}

$\mathrm{TB}=$ Tuberculosis; $\mathrm{SD}=$ Standard deviation, $\mathrm{n}=$ Number of cases, HIV = Human immunodeficiency virus, $\mathrm{IR}=$ Interquartile range.

*Approximately U\$ 312 (2013).

Group 1 than in Group 2 (82.3 versus 64.9\%, $\mathrm{p}=0.023$ ). In binary logistic regression analysis for patient delay, the factors that were independently associated with a time delay $\geq 30$ days were crack use $(\mathrm{OR}=4.88, \mathrm{p}=0.043)$ and cocaine use $(\mathrm{OR}=6.68, \mathrm{p}=0.011)$.

\section{Health care system delay}

Table 3 shows comparative analysis for health system delay. The proportion of patients reporting sputum production was significantly higher in Group $2(<18$ days for health care system delay) than in Group 1 ( $\geq 18$ days for health care system delay) ( 73.3 versus $55.1 \%, \mathrm{p}=0.029$ ), and the proportion of patients reporting previous TB (22.7 versus
$9.0 \%, \mathrm{p}=0.035)$ and patients with fibrotic changes on chest $\mathrm{X}$-ray $(17.3$ versus $2.6 \%, \mathrm{p}=0.005)$. In multivariate analysis, the factors that were independently associated with a time delay $\geq 18$ days were weight loss $(\mathrm{OR}=2.76, \mathrm{p}=$ $0.025)$, chest radiography with a miliary pattern $(\mathrm{OR}=5.33$, $\mathrm{p}=0.032)$, and fibrotic changes $(\mathrm{OR}=0.12, \mathrm{p}=0.013)$.

\section{Discussion}

This study evaluated patients diagnosed with TB in the ED of a university hospital, in a city with a high prevalence of this disease. The total time from symptom onset to the start of treatment was too long, and the delay attributed to the patient was greater than the delay attributed to the health system. The factors that were independently associated with patient delay were cocaine and crack use. Factors that were independently associated with health system delay were weight loss and miliary pattern on chest $\mathrm{X}$-rays, while the presence of fibrotic changes on chest radiography was negatively associated with health system delay. We did not find any association between delayed diagnosis and some factors usually associated with delay in previous studies, such as HIV infection, negative sputum smear, old age, female sex, low educational level, poverty, and smoking [6].

To date, there is no consensus on an "acceptable" time for a delay in diagnosis of TB, but it depends on the epidemiology and health services of each country [14]. In underdeveloped or developing countries with highly endemic $\mathrm{TB}$, the total time delay exceeds 120 days, while in many developing countries, the total time delay is approximately 50 days [6].

Brazil is considered a country with high endemic TB [1]. However, the total time delay until diagnosis of $\mathrm{TB}$ that we found ( 60 days) in the current study is unacceptably too long. A long time delay has also been reported by studies conducted in other regions of the country [8-10]. The southeast region reported total time delays of 68 days [8] and 77 days [9], and a study in the northeastern region reported a total time of 90 days [10]. These findings indicate that in Brazil, there is a need for greater awareness of the symptoms of TB. There is also a need for early diagnosis of TB to attempt to reduce this time to $3-4$ weeks as recommended by international guidelines for the control of disease [3].

In a systematic review [5], the total time delay in diagnosis in countries with low and highly endemic TB was 25 and 187 days, the patient delay was 4.9 and 162 days, and the health system delay was 2 and 87 days, respectively. Our study found similar time delays to those reported in Brazilian studies [8,9]; the median patient delay ranged from 30 to 56 days and the median health system delay ranged from 14 to 21 days.

We found an association between patient delay and drug use, particularly cocaine and crack. Patients who 
Table 2 Univariate analysis and logistic regression analysis for patient delay

\begin{tabular}{|c|c|c|c|c|c|c|c|c|}
\hline \multirow[t]{2}{*}{ Characteristics } & \multirow[t]{2}{*}{$\begin{array}{l}\text { Group } 1 \\
\text { ( } \geq 30 \text { days) }\end{array}$} & \multirow[t]{2}{*}{$\begin{array}{l}\text { Group } 2 \\
\text { (<30 days) }\end{array}$} & \multirow[b]{2}{*}{ OR } & \multicolumn{2}{|l|}{$\begin{array}{l}\text { Univariate } \\
\text { analysis }\end{array}$} & \multirow[b]{2}{*}{ Adjusted OR } & \multicolumn{2}{|l|}{$\begin{array}{l}\text { Logistic } \\
\text { regression }\end{array}$} \\
\hline & & & & $95 \% \mathrm{Cl}$ & $\mathbf{p}$ & & $95 \% \mathrm{Cl}$ & $p$ \\
\hline Age, years (mean $\pm S D$ ) & $44.8 \pm 16.0$ & $40.2 \pm 15.0$ & 0.98 & $0.96-1.01$ & 0.069 & 1.03 & $0.99-1.05$ & 0.064 \\
\hline Male sex, n (\%) & $51(64.6)$ & $39(52.7)$ & 1.28 & $0.92-1.78$ & 0.185 & 1.02 & $0.48-2.20$ & 0.960 \\
\hline White race, n (\%) & $42(53.2)$ & $46(62.2)$ & 0.84 & $0.62-1.14$ & 0.336 & & & \\
\hline$<8$ years schooling, $\mathrm{n}(\%)$ & $41(51.9)$ & $40(54.1)$ & 0.96 & $0.71-1.30$ & 0.916 & & & \\
\hline Literate, $\mathrm{n}(\%$ sim $)$ & $73(92.4)$ & $68(91.9)$ & 1.04 & $0.58-1.86$ & 0.999 & & & \\
\hline Living alone, n (\%) & $17(21.5)$ & $13(17.6)$ & 1.12 & $0.79-1.61$ & 0.681 & & & \\
\hline Belief in a religion, n (\%) & $65(82.3)$ & $61(82.4)$ & 1.00 & $0.66-1.49$ & 0.999 & & & \\
\hline 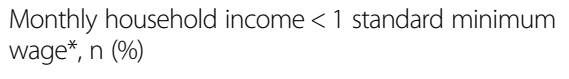 & $28(35.4)$ & $23(31.1)$ & 1.10 & $0.80-1.51$ & 0.689 & & & \\
\hline Living in Porto Alegre, n (\%) & $49(62.0)$ & $52(70.3)$ & 0.84 & $0.62-1.14$ & 0.365 & & & \\
\hline Institutionalization, n (\%) & $13(16.5)$ & $10(13.5)$ & 1.22 & $0.57-2.61$ & 0.778 & & & \\
\hline Current or former smoker & $56(70.9)$ & $42(56.8)$ & 1.35 & $0.99-1.87$ & 0.099 & 0.72 & $0.34-1.55$ & 0.397 \\
\hline Alcoholism, n (\%) & $27(34.2)$ & $26(35.1)$ & 0.98 & $0.71-1.36$ & 1.000 & & & \\
\hline Drug use, n (\%) & $32(40.5)$ & $18(24.3)$ & 1.40 & $1.04-4.25$ & 0.05 & 1.68 & $0.73-3.88$ & 0.225 \\
\hline Marijuana use, n (\%) & $16(20.3)$ & $13(17.6)$ & 1.09 & $0.75-1.57$ & 0.828 & & & \\
\hline Cocaine use, n (\%) & $22(27.8)$ & $5(6.8)$ & 1.80 & $1.38-2,34$ & 0.001 & 6.68 & $1.54-28.9$ & 0.011 \\
\hline Crack use, n (\%) & 25 (31.6) & $10(13.5)$ & 1.56 & $1.17-2.08$ & 0.013 & 4.88 & $1.05-22.74$ & 0.043 \\
\hline \multicolumn{9}{|l|}{ Symptoms, n (\%) } \\
\hline Cough & 70 (88.6) & $63(85.1)$ & 1.17 & $0.70-1.95$ & 0.692 & & & \\
\hline Night sweats & $55(69.6)$ & $47(63.5)$ & 1.15 & $0.81-1.61$ & 0.529 & & & \\
\hline Fever & $65(82.3)$ & $60(81.1)$ & 1.04 & $0.69-1.56$ & 0.999 & & & \\
\hline Sputum production & $56(70.9)$ & $42(56.8)$ & 1.37 & $0.96-1.95$ & 0.099 & & & \\
\hline Hemoptysis & $16(20.3)$ & $9(12.2)$ & 1.30 & $0.93-1.83$ & 0.257 & & & \\
\hline Weight loss & $62(78.5)$ & $55(74.3)$ & 1.12 & $0.76-1.65$ & 0.678 & & & \\
\hline Dyspnea & $52(65.8)$ & $43(58.1)$ & 1.17 & $0.85-1.64$ & 0.414 & & & \\
\hline Chest pain & $41(51.9)$ & $29(39.2)$ & 1.28 & $0.94-1.74$ & 0.157 & & & \\
\hline Fatigue & $32(40.5)$ & $21(28.4)$ & 1.29 & $0.95-1.74$ & 0.160 & & & \\
\hline HIV positive, n (\%) & $41(64.1)$ & $36(58.1)$ & 1.14 & $0.79-1.63$ & 0.612 & & & \\
\hline Non-HIV immunosuppression, n (\%) & $12(15.2)$ & $10(13.5)$ & 1.07 & $0.70-1.62$ & 0.948 & & & \\
\hline Sought care elsewhere before hospitalization, n (\%) & $65(82.3)$ & $48(64.9)$ & 1.64 & $1.05-2.58$ & 0.023 & & & \\
\hline Previous TB, n (\%) & $16(20.3)$ & $8(10.8)$ & 1.37 & $0.98-1.91$ & 0.167 & & & \\
\hline Completed treatment, n (\%) & $8(50.0)$ & $6(75.0)$ & 0.72 & $0.41-1.14$ & 0.388 & & & \\
\hline Knows someone with TB, n (\%) & $41(51.9)$ & $36(48.6)$ & 1.07 & $0.78-1.45$ & 0.810 & & & \\
\hline
\end{tabular}

$\mathrm{TB}=$ Tuberculosis; $\mathrm{SD}=$ Standard deviation, $\mathrm{n}=$ Number of cases, HIV = Human immunodeficiency virus.

*Approximately U\$ 312 (2013).

abuse substances are more susceptible to diseases and have a greater period of transmissibility of the disease, because they do not seek health services early, or use TB drugs irregularly [16]. Furthermore, in accordance with our findings, a previous study showed that drug users had a delay in initiation of treatment compared with patients who did not use drugs [17].

Despite TB control programs' recommendation that diagnosis should be made at the primary health care level, most patients are still diagnosed in hospitals, especially public hospitals $[18,19]$. In 2007, in Porto Alegre, 38.98\% of TB cases were reported by hospitals [20]. In our study, most patients with a diagnostic delay of longer than 30 days sought other health services before a hospital. Previous studies have shown that a delay in diagnosis is closely related to poor access to health care, either by distance from health services or difficulties in performing exams, and prescription of medications other than antituberculosis 
Table 3 Univariate analysis and logistic regression for health care system delay

\begin{tabular}{|c|c|c|c|c|c|c|c|c|}
\hline \multirow[t]{2}{*}{ Characteristics } & \multirow[t]{2}{*}{$\begin{array}{l}\text { Group } 1 \\
(\geq 18 \text { days) }\end{array}$} & \multirow[t]{2}{*}{$\begin{array}{l}\text { Group } 2 \\
(<18 \text { days })\end{array}$} & \multirow[b]{2}{*}{ OR } & \multicolumn{2}{|l|}{$\begin{array}{l}\text { Univariate } \\
\text { analysis }\end{array}$} & \multirow[b]{2}{*}{ Adjusted OR } & \multicolumn{2}{|l|}{$\begin{array}{l}\text { Logistic } \\
\text { regression }\end{array}$} \\
\hline & & & & $95 \% \mathrm{Cl}$ & $p$ & & $95 \% \mathrm{Cl}$ & $\mathbf{p}$ \\
\hline Age, years (mean $\pm S D$ ) & $43.8 \pm 15.83$ & $41.28 \pm 15.57$ & 0.99 & $0.97-1.01$ & 0.321 & 0.98 & $0.96-1.01$ & 0.081 \\
\hline Male sex, n (\%) & $47(60.3)$ & $43(57.1)$ & 1.06 & $0.77-1.76$ & 0.839 & 1.16 & $0.53-2.4$ & 0.720 \\
\hline White race, n (\%) & $48(61.5)$ & $40(53.3)$ & 1.18 & $0.85-1.64$ & 0.388 & & & \\
\hline Current or former smoker & $50(34.1)$ & $48(64.0)$ & 1.01 & $0.72-1.38$ & & & & \\
\hline Alcoholism, n (\%) & $31(39.7)$ & $22(29.3)$ & 1.24 & $0.92-1.69$ & 0.324 & & & \\
\hline Drug use, n (\%) & $26(33.3)$ & $24(32.0)$ & 1.03 & $0.74-1.43$ & 0.997 & & & \\
\hline Marijuana use, n (\%) & $16(20.5)$ & $13(17.3)$ & 1.10 & $0.76-1.60$ & 0.768 & & & \\
\hline Cocaine use, n (\%) & $17(21.8)$ & $10(13.3)$ & 1.30 & $0.93-1.83$ & 0.246 & & & \\
\hline Crack use, n (\%) & $18(23.1)$ & $17(22.7)$ & 1.01 & $0,70-1.46$ & 0.999 & & & \\
\hline Symptoms, n (\%) Cough & $66(84.6)$ & $67(89.3)$ & 0.83 & $0.56-1.23$ & 0.532 & & & \\
\hline Sputum production & $43(55.1)$ & $55(73.3)$ & 0.69 & $0.51-0.93$ & 0.029 & 0.45 & $0.20-1.01$ & 0.052 \\
\hline Hemoptysis & $12(15.4)$ & $13(17.3)$ & 0.93 & $0.60-1.45$ & 0.555 & & & \\
\hline Fever & $63(80.8)$ & $62(82.7)$ & 0.94 & $0.64-1.38$ & 0.925 & & & \\
\hline Weight loss & $65(83.3)$ & $52(69.3)$ & 1.54 & $0.97-2.45$ & 0.064 & 2.76 & $1.14-6.71$ & 0.025 \\
\hline Dyspnea & $49(62.8)$ & $46(61.3)$ & 1.03 & $0.75-1.43$ & 0.982 & & & \\
\hline Night sweats & $58(74.4)$ & $44(58.7)$ & 1.45 & $0.99-2.12$ & 0.059 & 1.74 & $0.77-3.93$ & 0.184 \\
\hline Chest pain & $36(46.2)$ & $34(45.3)$ & 1.01 & $0.74-1.39$ & 0.999 & & & \\
\hline Fatigue & $29(37.2)$ & $23(30.7)$ & 1.18 & $0.86-1.61$ & 0.408 & & & \\
\hline $\begin{array}{l}\text { Had consultation at the first health service } \\
\text { sought, } n(\%)\end{array}$ & $72(92.3)$ & $74(98.7)$ & 0.58 & $0.41-0.81$ & 0.135 & & & \\
\hline Chest x-ray performed, n (\%) & $65(90.3)$ & $69(93.2)$ & 0.94 & $0.69-1.28$ & 0.202 & & & \\
\hline Previous TB, n (\%) & $7(9.0)$ & $17(22.7)$ & 0.53 & $0.28-1.01$ & 0.035 & 0.50 & $0.15-1.66$ & 0.256 \\
\hline Completed treatment, n (\%) & $4(57.1)$ & $10(58.8)$ & 0.95 & $0.27-3.35$ & 0.999 & & & \\
\hline HIV positive, n (\%) & $42(60.9)$ & $35(61.4)$ & 0.99 & $0.72-1.37$ & 0.999 & & & \\
\hline \multicolumn{9}{|l|}{ Radiographic pattern, n (\%) } \\
\hline Cavitation & 12 (15.6) & $22(29.3)$ & 0.64 & $0.40-1.04$ & 0.066 & 0.45 & $0.19-1.08$ & 0.074 \\
\hline Pleural effusion & $4(5.1)$ & $2(2.7)$ & 1.32 & $0.74-2.39$ & 0.682 & & & \\
\hline Milliary pattern & $11(14.1)$ & $3(4.0)$ & & & 0.059 & 5.33 & $1.15-24.56$ & 0.032 \\
\hline Consolidation & $41(52.6)$ & $40(53.3)$ & & & 0.999 & & & \\
\hline Fibrotic changes & $2(2.6)$ & $13(17.3)$ & & & 0.005 & 0.12 & $0.02-0.64$ & 0.013 \\
\hline Reticular infiltrates & $28(35.9)$ & $21(28.0)$ & & & 0.382 & & & \\
\hline \multicolumn{9}{|l|}{ Forms of TB } \\
\hline Pulmonary TB & $75(96.2)$ & $74(98.7)$ & & & 0.620 & & & \\
\hline Pleuropulmonary TB & $3(3.8)$ & $1(1.3)$ & & & 0.640 & & & \\
\hline Pulmonary + milliary TB & $12(15.4)$ & $7(9.3)$ & & & 0.374 & & & \\
\hline
\end{tabular}

$\mathrm{TB}=$ Tuberculosis; $\mathrm{SD}=$ Standard deviation, $\mathrm{n}=$ Number of cases, $\mathrm{HIV}=$ Human immunodeficiency virus, $\mathrm{OR}=$ Odds ratio, $95 \% \mathrm{Cl}=95 \%$ confidence interval.

drugs $[6,10]$. This may indicate the need for training professionals at primary health care clinics to recognize $\mathrm{TB}$ symptoms, allowing early diagnosis and treatment.

Another factor related to health system delay in our study was weight loss. Similar studies have shown that weight loss is associated with a delay in diagnosis and treatment initiation $[10,21,22]$. Another study showed that weight loss is an independent predictor for pulmonary $\mathrm{TB}$ diagnosis [23]. Furthermore, the presence of radiographic changes, such as a miliary pattern, is associated with delayed initiation of treatment $[23,24]$. However, there is the possibility that weight loss and a military pattern on chest $\mathrm{X}$-ray are more likely to occur in someone who has had untreated TB for a long period, and these findings may in 
fact be a result of a delay in treatment. Fibrotic changes and previous $\mathrm{TB}$ were associated with a shorter time to initiation of treatment in our study. A history of previous TB has been reported as an independent predictor for pulmonary TB diagnosis, and fibrotic changes may be associated with some symptoms of TB, such as hemoptysis, which facilitates the diagnosis and prompt initiation of $\mathrm{TB}$ treatment [23].

Half of the patients included in our study were TBHIV patients. The TB-HIV co-infection rate in the city of Porto Alegre is the highest in the country (35\%) [25]. This high prevalence of TB-HIV co-infection is probably because the study hospital is a reference center for HIV patients in South Brazil. In addition, HIV infection was not significantly associated with delays in our study. HIV is known to delay TB diagnosis because of non-specific and atypical clinical presentation [26,27]. However, our findings are in agreement with other studies [28-30] that found no association between HIV positivity and delayed diagnosis. In a previous investigation, HIV-positive TB patients suffered more serious symptoms when TB was diagnosed, which prompted them to visit the hospital and increased the suspicion of TB by the clinician [30].

The main limitation of the present study is that we only used a sample of the population served by the hospital. A control group of individuals diagnosed and treated at primary care health clinics could be useful for identifying the factors related to a delay in diagnosis. Furthermore, the study was conducted in a single center and referral center in the public system, and probably included patients with more severe disease and lower socioeconomic status. These factors did not affect the results, but they are specifically applicable to populations similar to that in our study. In addition, we did not evaluate some factors related to health system delay, such as the type of provider (public, private, and complimentary), rural/urban residence, and availability and accessibility of services. Finally, there was the possibility of recall bias associated with the time in days from onset of symptoms to the first clinical care. Despite these concerns, our study still showed some interesting findings.

Although we found some delay in the health care system, patient delay appears to be more important. The main factor associated with patient delay was drug abuse (crack and cocaine). Drug users may have less access to routine medical care, potentially leading to delayed diagnosis. Moreover, in a study with marijuana users, patients reported that despite feeling ill and having increased coughing, they delayed seeking care until $\mathrm{TB}$ was advanced [31], resulting in an extended period of infectiousness [32,33]. In addition, another study demonstrated that patients who abuse substances are less likely to complete TB screening [34]. There is a need for public health interventions among drug users, focusing on TB education programs. The use of some successful strategies, such as needle exchange programs $[35,36]$, should also be considered.

\section{Conclusions}

In conclusion, this study shows that in patients with $\mathrm{TB}$ diagnosed in the ED, the total time from symptom onset to TB diagnosis is too long. Additionally, patient delay appears to be the main problem in delay in diagnosis of TB in our study setting. The main factor associated with patient delay is drug abuse (crack and cocaine). Control of TB and substance abuse programs need to be closely linked, and health interventions should focus on TB education programs.

\section{Competing interests}

The authors declare that they have no competing interests.

\section{Authors' contributions}

GND participated in the design of the study, collected the data, and wrote the manuscript. DRS participated in the conception and design of the study, performed statistical analysis, and wrote the manuscript. ACC and AMM collected the data and helped to draft the manuscript. PTRD participated in the conception and design of the study, performed statistical analysis, and wrote the manuscript. All authors read and approved the final manuscript.

\section{Funding source}

Fundo de Incentivo à Pesquisa do Hospital de Clínicas de Porto Alegre (FIPE-HCPA).

Received: 30 April 2013 Accepted: 5 November 2013

Published: 13 November 2013

\section{References}

1. World Health Organization: Global Tuberculosis Report 2012. 2012. Available at: www.who.int

2. Prefeitura Municipal de Porto Alegre: Boletim Epidemiológico. 2012. Avalilable at: www.portoalegre.rs.gov.br.

3. Tuberculosis Coalition for Technical Assistance: International Standards for Tuberculosis Care (ISTC). 2006. Available at: www.who.int.

4. Lambert ML, Van der Stuyft P: Delays to tuberculosis treatment: shall we continue to blame the victim? Trop Med Int Health 2005, 10:945-946.

5. Sreeramareddy CT, Panduru KV, Menten J, Van den Ende J: Time delays in diagnosis of pulmonary tuberculosis: a systematic review of literature. BMC Infect Dis 2009, 9:91.

6. Storla DG, Yimer S, Bjune GA: A systematic review of delay in the diagnosis and treatment of tuberculosis. BMC Public Health 2008, 8:15.

7. Watkins RE, Plant AJ: Pathways to treatment for tuberculosis in Bali: patient perspectives. Qual Health Res 2004, 14:691-703.

8. Machado AC, Steffen RE, Oxlade O, Menzies D, Kritski A, Trajman A: Factors associated with delayed diagnosis of pulmonary tuberculosis in the state of Rio de Janeiro, Brazil. J Bras Pneumol 2011, 37:512-520.

9. Maior ML, Guerra RL, Cailleaux-Cezar M, Golub JE, Conde MB: Time from symptom onset to the initiation of treatment of pulmonary tuberculosis in a city with a high incidence of the disease. J Bras Pneumol 2012, 38:202-209.

10. dos Santos MA, Albuquerque MF, Ximenes RA, Lucena-Silva NL, Braga C, Campelo AR, et al: Risk factors for treatment delay in pulmonary tuberculosis in Recife, Brazil. BMC Public Health 2005, 5:25.

11. Lorent N, Mugwaneza P, Mugabekazi J, Gasana M, Van BS, Clerinx J, et al: Risk factors for delay in the diagnosis and treatment of tuberculosis at a referral hospital in Rwanda. Int J Tuberc Lung Dis 2008, 12:392-396

12. Ministério da Saúde: Indicadores de morbidade e fatores de risco. Brasil: Taxa de incidência de AIDS; 2006. Ref Type: Generic. 
13. Conde MB, Melo FA, Marques AM, Cardoso NC, Pinheiro VG, Dalcin PT, et al: III Brazilian thoracic association guidelines on tuberculosis. J Bras Pneumol 2009, 35:1018-1048

14. Ward J, Siskind V, Konstantinos A: Patient and health care system delays in Queensland tuberculosis patients, 1985-1998. Int J Tuberc Lung Dis 2001, 5:1021-1027.

15. Rossato SD, Muller AM, Dalcin PT: Factors associated with delayed diagnosis of tuberculosis in hospitalized patients in a high TB and HIV burden setting: a cross-sectional study. BMC Infect Dis 2012, $12: 57$

16. Oeltmann JE, Kammerer JS, Pevzner ES, Moonan PK: Tuberculosis and substance abuse in the United States, 1997-2006. Arch Intern Med 2009 169:189-197.

17. Shamaei M, Marjani M, Baghaei P, Chitsaz E, Rezaei TE, Abrishami Z, et al: Drug abuse profile - patient delay, diagnosis delay and drug resistance pattern - among addict patients with tuberculosis. Int J STD AIDS 2009, 20:320-323.

18. Sherman LF, Fujiwara PI, Cook SV, Bazerman LB, Frieden TR: Patient and health care system delays in the diagnosis and treatment of tuberculosis. Int J Tuberc Lung Dis 1999, 3:1088-1095.

19. Zerbini E, Chirico MC, Salvadores B, Amigot B, Estrada S, Algorry G: Delay in tuberculosis diagnosis and treatment in four provinces of Argentina. Int $J$ Tuberc Lung Dis 2008, 12:63-68.

20. Prefeitura Municipal de Porto Alegre: Boletim Epidemiológico. Porto Alegre, Brasil; 2008. Available at: www.portoalegre.rs.gov.br.

21. Lacroix C, Martin P, Turcotte S, DeRoche S, Magluilo V, Lacroix C: The delay in diagnosis of tuberculosis in the Monteregie region of Quebec, Canada. Mcgill J Med 2008, 11:124-131.

22. Schneider D, McNabb SJ, Safaryan M, Davidyants V, Niazyan L, Orbelyan S: Reasons for delay in seeking care for tuberculosis, republic of armenia, 2006-2007. Interdiscip Perspect Infect Dis 2010, 2010:412624

23. Solari L, Acuna-Villaorduna C, Soto A, Agapito J, Perez F, Samalvides F, et al: A clinical prediction rule for pulmonary tuberculosis in emergency departments. Int J Tuberc Lung Dis 2008, 12:619-624.

24. Lin CY, Lin WR, Chen TC, Lu PL, Huang PM, Tsai ZR, et al: Why is in-hospital diagnosis of pulmonary tuberculosis delayed in southern Taiwan? J Formos Med Assoc 2010, 109:269-277.

25. Ministério da Saúde: Programa Nacional de Controle da Tuberculose. 2011 Available at: www.saude.gov.br.

26. Kramer F, Modilevsky T, Waliany AR, Leedom JM, Barnes PF: Delayed diagnosis of tuberculosis in patients with human immunodeficiency virus infection. Am J Med 1990, 89:451-456

27. Needham DM, Foster SD, Tomlinson G, Godfrey-Faussett P: Socio-economic, gender and health services factors affecting diagnostic delay for tuberculosis patients in urban Zambia. Trop Med Int Health 2001, 6:256-259.

28. Franco J, Blanquer R, Flores J, Fernandez E, Plaza P, Noqueira JM Analysis of the diagnostic delay in tuberculosis. Med Clin (Barc) 1996, 107:453-457.

29. Lawn SD, Afful B, Acheampong JW: Pulmonary tuberculosis: diagnostic delay in Ghanaian adults. Int J Tuberc Lung Dis 1998, 2:635-640

30. Ngamvithayapong J, Yanai H, Winkvist A, Diwan V: Health seeking behaviour and diagnosis for pulmonary tuberculosis in an HIVepidemic mountainous area of Thailand. Int J Tuberc Lung Dis 2001, 5:1013-1020

31. Oeltmann JE, Oren E, Haddad MB, Lake L, Harrington TA, ljaz K, et al: Tuberculosis outbreak in marijuana users, Seattle, Washington, 2004. Emerg Infect Dis 2006, 12:1156-1159.

32. Chin DP, Crane CM, Diul MY, Sun SJ, Agraz R, Taylor S, et al: Spread of Mycobacterium tuberculosis in a community implementing recommended elements of tuberculosis control. JAMA 2000, 283:2968-2974.

33. Malakmadze N, Gonzalez IM, Oemig T, Isiadinso I, Rembert D, McCauley MM, et al: Unsuspected recent transmission of tuberculosis among high-risk groups: implications of universal tuberculosis genotyping in its detection. Clin Infect Dis 2005, 40:366-373.

34. Malotte CK, Rhodes F, Mais KE: Tuberculosis screening and compliance with return for skin test reading among active drug users. Am J Public Health 1998, 88:792-796.

35. Perlman DC, Gourevitch MN, Trinh C, Salomon N, Horn L, Des Jarlais DC: Cost-effectiveness of tuberculosis screening and observed preventive therapy for active drug injectors at a syringe-exchange program. J Urban Health 2001, 78:550-567.

36. Riley ED, Vlahov D, Huettner S, Beilenson P, Bonds M, Chaisson RE: Characteristics of injection drug users who utilize tuberculosis services at sites of the Baltimore city needle exchange program. J Urban Health 2002, 79:113-127.

doi:10.1186/1471-2334-13-538

Cite this article as: Deponti et al:: Delayed diagnosis and associated factors among new pulmonary tuberculosis patients diagnosed at the emergency department of a tertiary care hospital in Porto Alegre, South Brazil: a prospective patient recruitment study. BMC Infectious Diseases 2013 13:538.

\section{Submit your next manuscript to BioMed Central and take full advantage of:}

- Convenient online submission

- Thorough peer review

- No space constraints or color figure charges

- Immediate publication on acceptance

- Inclusion in PubMed, CAS, Scopus and Google Scholar

- Research which is freely available for redistribution 